\title{
Betriebssicherheit rund um die Uhr
}

\author{
In der Abwasseraufbereitung ist mangelnde Betriebssicherheit bei Filterpressen eine häufige
}

Schwachstelle. Bei der Entwicklung eines neuen Vollautomaten wurden verfahrenstechnische

Besonderheiten realisiert, die Verfügbarkeit rund um die Uhr ohne Personaleinsatz sicherstellen sollen.

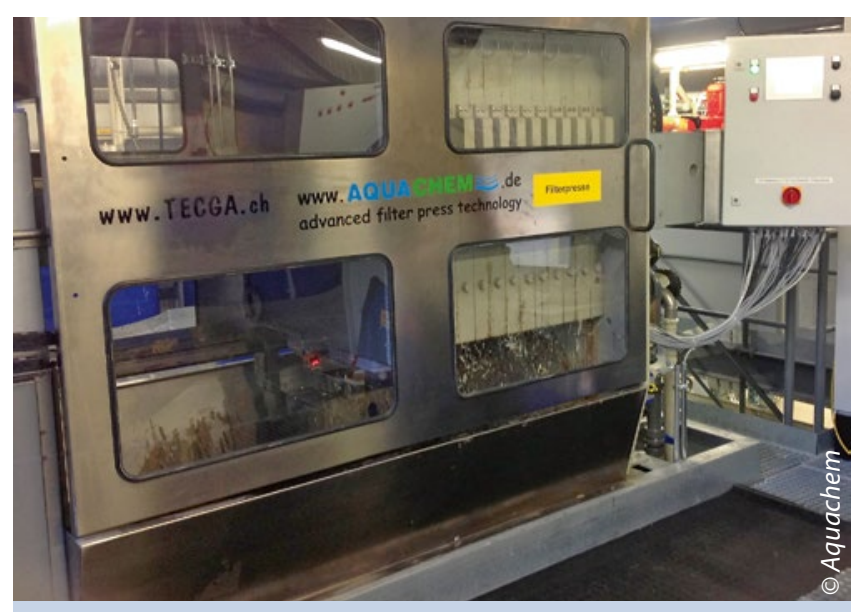

Undichtigkeiten beim Plattenpaket können zum Austreten der Suspension führen, was wiederum eine Gefahrenquelle für den Mitarbeiter darstellt. Die vollautomatische Filterpresse arbeitet dank abgedichteter Filterplatten und SPS-Steuerung rund um die Uhr sauber und zuverlässig.

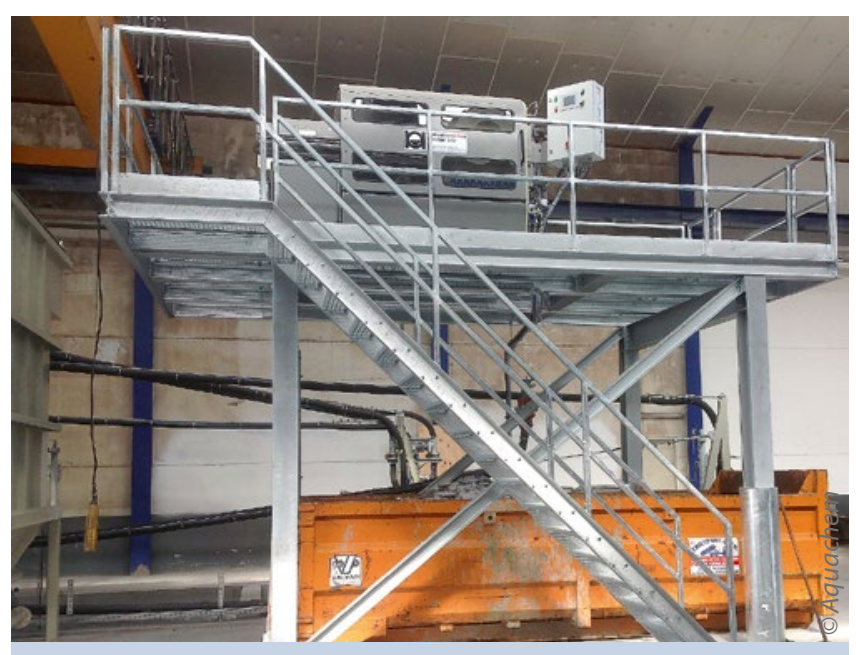

Da die Automaten nahezu beliebig oft entleert werden können, kann die Presse relativ klein gebaut werden. So braucht der Vollautomat nur etwa ein Sechstel der Fläche einer konventionellen Presse.
Z war ist die eigentliche Beschickung konventioneller Filterpressen bei allen Herstellern weitgehend automatisiert, die Entleerung läuft jedoch bestenfalls vollmechanisiert ab. Darunter leidet unter Umständen die Betriebssicherheit und auch der vollständige $\mathrm{Ku}-$ chenaustrag ist nicht unbedingt gewährleistet, so dass beim Wiederanlauf unter Umständen Undichtigkeiten auftreten. Außerdem muss der Mitarbeiter oft rein visuell entscheiden, ob der Zyklus abgeschlossen ist und die Presse aufgefahren werden kann. Dementsprechend kommt es immer wieder zu Fehlern und - im schlechtesten Fall zu einer Verschmutzung der Betriebsräume.

\section{Optimales Filtrationsergebnis \\ auch bei schwankenden \\ Bedingungen}

Die Vollautomaten der AF-Serie von Aquachem sind hingegen standardmä- ßig mit abgedichteten Filterelementen ausgeführt. Das ist Grundvoraussetzung, um die Maschinen im Betrieb sauber zu halten. Für einen sicheren Einsatz hat der Hersteller darüber hinaus ein neues Steuerungskonzept entwickelt: Über eine SPS mit Visualisierung lassen sich alle gängigen Beschickungspumpen Druck-Mengen-abhängig regeln, so dass auch bei schwankenden Bedingungen Personenschutz, Sauberkeit und Sicherheit im Betrieb bei gleichzeitig optimalem Filtrationsergebnis gewährleistet sind. Wenn sich beispielsweise die Dichte ändert, wird das erkannt und der Zyklus entsprechend angepasst, so dass die Qualität des Filterkuchens am Ende stimmt.

Grundsätzlich kann über vier Parameter jede beliebige Kennlinie gefahren werden und auch Rezeptursprünge sind möglich.

Die Anlage startet selbsttätig, wenn genügend Masse da ist, um den Zyklus zu beenden. Somit kann die Filterpresse auch komplett unbeaufsichtigt laufen. Die einzigen Aufgaben, für die das Personal noch benötigt wird, ist das gelegentliche Wechseln der Reststoffbehälter oder Big Bags sowie die täglichen Sichtprüfungen. Zusätzlich wird empfohlen einmal pro Woche die Dichtränder zu reinigen.

Die Pressen sind standardisiert, was eine effiziente Fertigung erlaubt und ein gutes Preis-Leistungs-Verhältnis ermöglicht. Somit rechnet sich die Anschaffung nicht nur als Ersatz, sondern auch als Neuinvestition, da sich diese aufgrund der Einsparungen - unter anderem wegen der reduzierten Personalkosten - innerhalb kürzester Zeit amortisiert. I

\section{0\&S: Halle 9, Stand B 49}

Kontakt

www.aquachem.de 